\title{
A Case of Multi-Stage Fracturing Horizontal Well Used in BZ Oilfield in Bohai Bay Low-Permeability Oilfield Development
}

\author{
Xiujuan Zhao*, Chuanjun Wang, Quanlin Wang, Jie Tan, Wei Yang \\ Bohai Oilfield Research Institute of CNOOC Ltd.-Tianjin Branch, Tianjin, China \\ Email: ${ }^{\star} 16890452 @ q q . c o m$
}

How to cite this paper: Zhao, X. J., Wang, C. J., Wang, Q. L., Tan, J., \& Yang, W. (2020). A Case of Multi-Stage Fracturing Horizontal Well Used in BZ Oilfield in Bohai Bay Low-Permeability Oilfield Development. Journal of Geoscience and Environment Protection, 8, 147-154

https://doi.org/10.4236/gep.2020.87008

Received: June 24, 2020

Accepted: July 25, 2020

Published: July 28, 2020

Copyright $\odot 2020$ by author(s) and Scientific Research Publishing Inc. This work is licensed under the Creative Commons Attribution International License (CC BY 4.0).

http://creativecommons.org/licenses/by/4.0/

\section{(c) (i) Open Access}

\begin{abstract}
BZ oilfield in Bohai Bay of China was a typical offshore low permeability oilfield, which was restricted by many factors such as environment and economy. In this paper, the development characteristics of BZ oilfield were summarized in depth, and the new development mode of offshore low-permeability oilfield was explored from reservoir prediction, well spacing and fracturing technology. Taking BZ oilfield as an example, a set of technical system for the effective development of offshore low permeability oilfield had been formed through research, which mainly includes reservoir prediction and evaluation of offshore middle and deep low permeability oilfield, optimization of horizontal well pattern, multi-stage fracturing design of horizontal well and other technologies. The results show that improving the resolution of seismic data, strengthening the analysis of seismic reflection characteristics and carrying out the comprehensive study of seismic geology were the keys to solve the reservoir prediction of offshore low-permeability oil fields. Multi-stage fracturing horizontal well pattern is the main pattern of offshore low-permeability oilfield development. The parameters of multi-stage fracturing horizontal well together affect the development effect. Selecting the optimal fractured horizontal well pattern can greatly improve the development effect. The successful combination and application of new technology system was the foundation and core of conquering offshore low-permeability oil fields. On the basis of understanding the geological characteristics of oil reservoirs, it is an effective means of developing offshore low-permeability oil fields by selecting reasonable production methods, well types and well patterns. Using efficient perforation and fracturing technology to successfully control fracture parameters and form optimal injection and production well pattern was the key to improve low permeability offshore oil fields.
\end{abstract}




\section{Keywords}

Low Permeability, Offshore Oil Field, Multi-Stage Fracturing, Horizontal Well Pattern

\section{Introduction}

With the deepening of oil and gas exploration and development in BZ Oilfield, the share of low permeability reserves in the new reserves of BZ Oilfield was increasing. The successful development of offshore low permeability oilfield will become an important potential for the development of offshore oil industry, which had important practical and far-reaching strategic significance for the realization of the sustained and stable production of offshore oil fields. BZ oil field was a typical low-permeability offshore oil field. Located at the boundary between Bozhong sag and Bonan Low uplift in Bohai Bay Basin, it was a paleogene structural oil reservoir with deep burial, high original formation pressure, poor physical properties and complex fault blocks. Of land characteristics of low permeability oil field was a deep research, formed a relatively complete system of (Chen, 2006; Li, 1997; Huang, 1998; Wang et al., 2011; He, 1999; Hui et al., 2011; Wang et al., 2012a), but offshore oil field was influenced by many factors, such as economic, environmental development of low permeability oilfield development, which should be closely combined with the reservoir geological characteristics, further study of Marine low permeability oil field production characteristics, optimize the development way, explore the reasonable development of low permeability oilfield by sea mode.

\section{Reservoir Characteristics}

\subsection{Lithology and Lithofacies Characteristics}

The lithology of the reservoir in Sha2 member of BZ oilfield was medium-coarse sandstone of lithic feldspar. The particles were in the form of sub-ribose and sub-circular. The lithic composition was mainly intrusive rock, metamorphic rock and extrusive rock. The lithology of sha 3 reservoir was lithic arkose coarse sandstone or greywacke, with coarse grain size and poor sorting. The grains were mostly in the shape of secondary rims with low structural maturity. The lithic composition was mainly intrusive rock, metamorphic rock and extrusive rock. Braided river delta deposits were mainly developed in sha2 member of $\mathrm{BZ}$ oilfield, which was a small continental shallow water lake. The sedimentary subfacies were mainly composed of braided river delta front and prodelta deposits. Fan delta sedimentary facies were mainly developed in the third member of Sha, including fan delta plain subfacies, fan delta front subfacies and front fan delta subfacies.

\subsection{Reservoir Physical Characteristics}

In BZ oilfield of Bohai Bay, the rock pores in the second section of Sand were 
well developed and evenly distributed, mainly intergranular pores with a general pore size of $0.05-0.2 \mathrm{~mm}$, narrow pore throat and general connectivity. Occasionally, feldspar insoluble pores can be seen, and they were characterized by compaction. The average porosity is $16.7 \%$, and the average permeability is $28.0 \times$ $10^{-3} \mathrm{~m}^{2}$. The average porosity $14.5 \%$, among which the average low-permeability average permeability $17.6 \times 10^{-3} \mathrm{~m}^{2}$ and the average ultra-low-permeability average permeability $1.0 \times 10^{-3} \mu \mathrm{m}^{2}$.

\subsection{Temperature and Pressure Characteristics}

Sha Formation reservoir in BZ oilfield was characterized by high temperature and abnormal high pressure system, and the reservoir temperature $127^{\circ} \mathrm{C}$ $135^{\circ} \mathrm{C}$. The pressure coefficient of the second sand Section $1.40-1.57$, and the formation pressure 42.0 - $45.8 \mathrm{mpa}$. The pressure coefficient of the third Section 1.51 - 1.59, and the formation pressure 49.0 - 57.0 MPa. In summary, BZ oil field in Bohai Bay divided by multiple faults, with medium porosity, low permeability and abnormal pressure system.

\section{Development Characteristics of BZ Oilfield}

BZ oilfield had poor reservoir physical properties. Due to the limitation of cost, it was difficult to establish effective injection-production spacing due to the large spacing of injection and production wells. The development process was mainly manifested as the following characteristics: 1) Imperfect well pattern, low water cut during production, low oil recovery rate and low recovery degree; 2) The initial production of conventional low-permeability reservoir oil wells was high, and the production decline fast. The initial production of ultra-low-permeability reservoir oil wells after fracturing were put into operation, but the production decline was very fast. 3) Offshore well layout adopts the principle of "fewer wells and more control", resulting in low production degree of reservoir reserves and limited effective control reserves of single well; 4) Reservoir was abnormal high pressure, the early use of depletion type of production, formation pressure drop fast; 5) It was difficult to inject water, slow to take effect, and requires high water quality. The average daily water injection volume of the current test injection well is $60 \mathrm{~m}^{3} / \mathrm{d}$.

\section{Prediction and Evaluation of Middle and Deep Reservoirs in BZ Oilfield}

The reservoir in BZ oilfield buried deep, with thin single sand body thickness and low resolution of seismic data. In view of the poor quality of seismic data in oil reservoirs, high density, high resolution, wide band and wide azimuth targets were adopted to improve the resolution quality of seismic data in BZ oilfield. In the research, the target processing of seismic data was carried out to tap the potential of existing data and improve the quality of data. After reprocessing, the sand body stages can be clearly depicted, which lays a foundation for reservoir 
description. Through the analysis of fine paleogeomorphology, the characterization of seismic and sedimentary facies, the stochastic inversion before stack, the interpretation of multi-attribute convergence and the key factors controlling the reservoir physical properties, the reservoir prediction under the constraint of phase-controlled model was formed. The results show that the reservoir in the lower part of the second and third member was developed, while the upper part of the third member was relatively undeveloped, and the lateral variation of the reservoir sand body was great.

Therefore, through the study on the prediction of medium and deep reservoirs, it showed that improving the resolution of seismic data, strengthening the analysis of seismic reflection characteristics and carrying out the comprehensive study of seismic geology were the keys to solve the reservoir prediction of offshore low-permeability oil fields (Wang et al., 2012b; Liu et al., 2008).

\section{Effective Development Strategy of BZ Oilfield}

\subsection{Optimization of Development Mode and Waterflood Timing}

In $\mathrm{BZ}$ oilfield of Bohai Bay, the original formation pressure was high, the ground saturation pressure difference was large (23.2 - 33.4 MPa), the formation crude oil had good physical property (viscosity $0.44-1.25 \mathrm{MPa}$. S, density $0.661-0.745$ $\mathrm{g} / \mathrm{cm}^{3}$ ), and the water body was not active. According to the characteristics of the reservoir, the comparative analysis of various development methods shows that it was suitable to adopt the early depletion development, and then adopt the waterflood development to improve the recovery after the pressure drops to the normal level.

\subsection{Reasonable Well Spacing, Well Type and Pattern Optimization}

At present, a large number of low permeability reservoirs have not been put into development, so there was no mature experience for reference. According to the actual land low permeability oilfield injection-production well spacing and calculation methods, respectively to calculate the limit of directional well and horizontal well injection-production well spacing (Figure 1, Figure 2), the results show that the directional limit injection-production well spacing $100-400 \mathrm{~m}$, the horizontal limit injection-production well spacing $200-800 \mathrm{~m}$, therefore of sand and sand three conventional low permeability part of high permeability, high Angle directional well and can be used well developed, but the three sections of extra low permeability sand reservoir horizontal well development should be adopted.

When the reservoir extra-low permeability, the spacing between injection and production wells of horizontal wells still small, the density of well pattern large, and the inter layer distribution, it was difficult to use the reservoir longitudinally, resulting in low recovery rate and increased development cost. Therefore, multi-stage fracturing horizontal wells were considered to exploit extra-low permeability reserves. According to the $100 \mathrm{~m}$ of injection-production spacing 


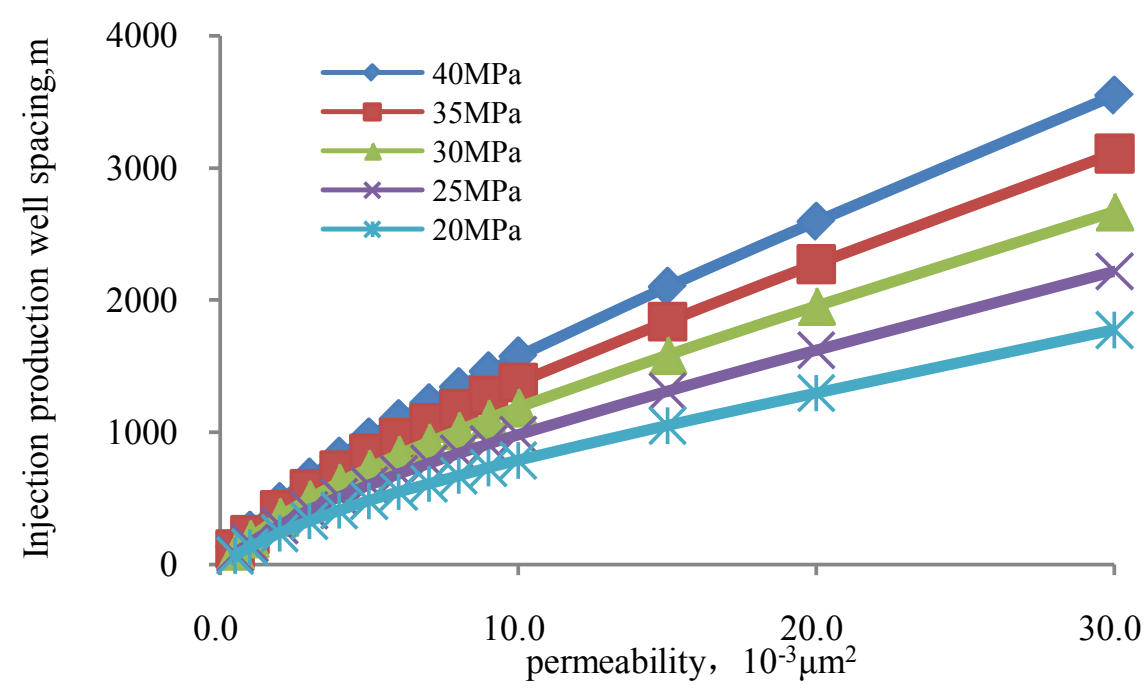

Figure 1. Calculation results of directional well spacing in BZ Oilfield.

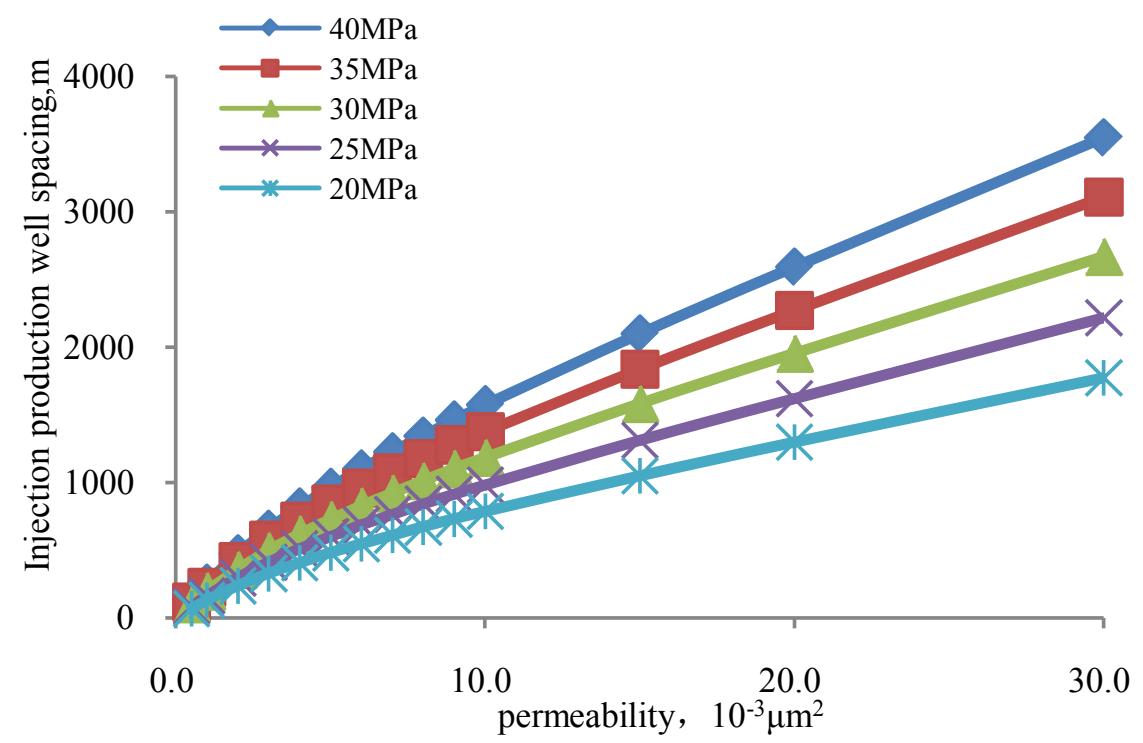

Figure 2. Calculation results of horizontal well spacing in BZ Oilfield.

calculated by directional wells, considering the $100 \mathrm{~m}$ of fracture length and 60 $\mathrm{m}$ of fracture height, set the spacing of multistage fractured horizontal wells at 300 and $350 \mathrm{~m}$, and infuse the meshes with unequal spacing to simulate the seepage of fractures. The results of the study show that multistage fractured horizontal wells were $300 \mathrm{~m}$ better than $350 \mathrm{~m}$, with a $5.0 \%$ increase in recovery and a better water flooding effect with a final moisture content of $91.5 \%$. It can be seen that multi-stage fracturing horizontal wells were used in the development of ultra-low permeability reservoirs, with injection and production wells spaced up to $300 \mathrm{~m}$ apart, and good development results can be achieved. Effect diagram of water flooding in different well distances of multi-stage fracturing horizontal wells.

Therefore, by integrating similar methods of oilfield and reservoir engineering 
and numerical simulation, it determined that the conventional low-permeability part of $\mathrm{X}$ oilfield can be combined with directional well and multi-stage fractured horizontal well irregular well pattern, while the extra-low-permeability reservoir should be developed with multi-stage fractured horizontal well pattern and parallel fractures in horizontal wells.

\subsection{Parameter Optimization of Multistage Fracturing Horizontal Wells}

\subsubsection{Length Optimization of Horizontal Wells According to Reservoir Parameters}

8 kinds of horizontal Wells were designed in length $(100-800 \mathrm{~m})$. Through analysis and comparison of annual oil production and cumulative oil production, it can be seen that: 1) cumulative oil production increases with the increase of horizontal section length, but the increase decreases after the horizontal well length increases to $500 \mathrm{~m}$; 2) A longer stage of higher oil production at the initial stage, but the decline rate greater. Therefore, comprehensive analysis shows that the reasonable horizontal well length of $\mathrm{BZ}$ oilfield about $500 \mathrm{~m}$. Production comparison of horizontal wells with different horizontal section lengths

\subsubsection{Fracturing Bar Number and Half-Length Optimization of Horizontal Wells}

A large number of literature studies have shown that if too many fractures were fractured along the horizontal well section, the width of each fracture may decrease and the fractures were too dense. At first, the productivity greatly improved, but after about a year, the effect becomes worse (Hoch et al., 2003). According to the horizontal well $500 \mathrm{~m}$ long and the fracture half $100 \mathrm{~m}$ long, the oil production of different fracture strips in the initial stage was compared and analyzed. The results showed that the initial yield increased with the number of cracks, but the yield increase decreased when the number of cracks was more than 4 , and decreased when the number of cracks was more than 6 . Therefore, the number of fractures in multistage fracturing horizontal wells about 5. Production comparison of different fracture lines in multistage fractured horizontal wells The fracture half-length also an important parameter that affects the production of multi-stage fractured horizontal wells. The designed horizontal well $500 \mathrm{~m}$ long and had 5 fractures. The analysis and comparison of daily yields of different fracture lengths at the initial stage showed that the initial yield increased with the increase of fracture lengths, but the increase rate decreased after the fracture lengths grew to $80 \mathrm{~m}$, and the increase rate was smaller after the fracture lengths were larger than $110 \mathrm{~m}$. Therefore, the fracture length $80-110$ $\mathrm{m}$ during fracturing. Considering the scale and cost of offshore fracturing, the fracture length should be controlled within $100 \mathrm{~m}$. Production comparison of different fracture lengths in multi-stage fractured horizontal wells.

\section{Perforation and Horizontal Well Fracturing Technology}

In low-permeability reservoirs, efficient perforation technologies with deep pe- 
netration, high strength, tubing transmission and negative pressure can improve the degree of perfection and production capacity of low-permeability reservoir oil wells, while for deep ultra-low-permeability oil wells, formation fracture pressure can be reduced and fracturing effect can be enhanced (Zhu et al., 2012). Fracturing reservoir is an effective method to greatly improve the development effect of low-permeability oilfield. Taking the whole reservoir as the research object, taking single well output, production degree and water cut rise rate as the optimal design objectives, the optimal matching relationship between well pattern and fracture pattern studied in combination with reservoir engineering. In the optimization design project, it was necessary to have a clear understanding of the direction of ground stress, reservoir heterogeneity, natural fracture development and other conditions, so as to control artificial fracture parameters in an optimal way, so as to achieve maximum sustainable high and stable yield and improve economic benefits. Under the principle of overall optimal design, it was also necessary to optimize the engineering design and construction parameters of single well, monitor the construction process and fracture direction, and analyze and evaluate the production effect of fracturing in the later stage.

\section{Conclusion}

A set of effective system was formed developing offshore low permeability oilfield technology, mainly including offshore horizontal wells in low permeability oilfield reservoir prediction and evaluation. Well pattern optimization, multi-stage fracturing optimization, horizontal well fracturing technology and optimization perforating technology, and combining were very important in application of new technology system. At present, after the wells fractured put into production, the production declined very fast, which had a great impact on the recovery rate. Therefore, it was still necessary to strengthen the research on the repeated fracturing technology in offshore low-permeability oil fields in the later stage, so as to improve the final recovery rate of oil fields more greatly.

\section{Conflicts of Interest}

The authors declare no conflicts of interest regarding the publication of this paper.

\section{References}

Chen, R. Q. (2006). Optimization of Water Injection Development Scheme for Subdivision of Complex Fault-Block Reservoirs. Fault-Block Oil and Gas Field, 13, 29-30.

He, Y., Wu, H. B., \& Wu, N. S. (1999). A Low Permeability Reservoir Development Technology. Journal of Drilling Technology, 22, 20-23.

Hoch, O., Stromquist, M., Love, G., \& Argan, J. (2003). Multiple Precision Hydraulic Fractures of Low-Permeability Horizontal Openhole Sandstone Wells. SPE Annual Technical Conference and Exhibition, Denver, CO, 5-8 October 2003. https://doi.org/10.2118/84163-MS

Huang, Y.-Z. (1998). Seepage Mechanism of Low Permeability Reservoirs (pp. 18-20). 
Beijing: Petroleum Industry Press.

Li, D. P. (1997). Development of Low Permeability Sandstone Oilfield (pp. 1-10). Beijing: Petroleum Industry Press.

Liu, S., Cheng, Q., Yang, D. et al. (2008). Abnormal High Pressure Low Permeability Sandstone Reservoir Development Strategy. Journal of China Offshore Oil and Gas, 20, 382-385.

Hui, R., \& Wang, X. D. (2011). Dual Medium Low Permeability with Start-Up Pressure Gradient of Unsteady Seepage Study. Journal of China Offshore Oil and Gas, 23, 318-321.

Wang, C. J., Zhao, X. J., Lei, Y., Bohai, B. Z. et al. (2012a). Oilfield Efficient Development Strategy Research. Journal of Chongqing Institute of Technology (Natural Science Edition), 14, 36-39.

Wang, Q. L., Tang, H., Lu, D. L. et al. (2011). Experimental Study on Starting Pressure Gradient in Low Permeability Reservoirs. Oil and Gas Geology and Recovery, 18, 97-100.

Wang, Q. L., Zhao, X.-J., Xue, Y.-X. et al. (2012b). Horizontal Wells in Reservoir with Low Permeability Thin Interbed Multiple Fracturing Optimization Research (pp. 537-540). The Fifth National Special Reservoirs Technology Seminar Outstanding Papers.

Zhu, T. S., \& Xu, Y. G. (2012). Fracturing Technology for Ultra-Low Permeability Reservoirs (p. 56). Beijing: Petroleum Industry Press. 